\title{
SCIENTIFIC REPORTS

\section{Association of Insulin-like Growth Factor 1 Concentrations with Risk for and Prognosis of Amyotrophic Lateral Sclerosis - Results from the ALS Registry Swabia}

\author{
Gabriele Nagel (1) ${ }^{1}$, Raphael S. Peter (1) ${ }^{1}$, Angela Rosenbohm², Wolfgang Koenig ${ }^{3,4}$, \\ Luc Dupuis ${ }^{5}$, Dietrich Rothenbacher ${ }^{1 *} \&$ Albert C. Ludolph ${ }^{2}$
}

We investigated the associations of serum concentration of insulin-like growth factor 1 (IGF1) with risk and prognosis of ALS in the ALS registry (October 2010-June 2014, median follow-up 67.6 months) in a case-control and cohort study, respectively. Serum samples were measured for IGF-1. Information on covariates was collected by standardized questionnaire. We applied conditional logistic regression to appraise the risk and Cox proportional hazards models to appraise the prognostic value of IGF-1. Data of 294 ALS patients (mean age 65.4 (SD 11.0) years, $60.2 \%$ men) and 504 controls were included in the case-control study. Median serum IGF-1 concentrations were slightly higher in ALS cases than in controls ( $101 \mathrm{vs} .99 .5 \mathrm{ng} / \mathrm{ml}$ ). IGF-1 concentrations were not associated with ALS risk in the fully adjusted model (top vs. bottom quartile: OR $1.16 ; 95 \%-\mathrm{Cl} 0.73-1.84$, $\mathrm{p}$ for trend $=0.44$ ). Among 293 ALS cases (mean age 65.5 (SD 10.5) years, 56.8\% men) 243 died during follow-up. We found a statistically significant inverse association between continuous IGF-1 concentrations and survival $(p=0.01)$. Very high values IGF-1 were associated with a better prognosis of ALS suggesting that functions related to IGF-1 could be involved in survival.

Amyotrophic lateral sclerosis (ALS) is a neurodegenerative disease of largely unknown etiology leading to death within 3-4 years after diagnosis ${ }^{1}$. There is growing evidence that a disturbed energy metabolism in ALS could play a pathogenic role ${ }^{2}$. Data from the ALS registry Swabia showed a possible positive association of body mass index (BMI) with ALS decades before the clinical manifestation of $\mathrm{ALS}^{3}$. In the ALS cases, there was a sharp kink in BMI trajectories shortly before onset of ALS, and greater weight loss was associated with a worse prognosis ${ }^{3}$. A further investigation has shown that serum concentrations of leptin and adiponectin, two key hormones of the energy metabolism, are strongly and independently of the BMI associated with the ALS risk. Serum leptin levels were also negatively associated with overall survival of ALS patients ${ }^{4}$.

Insulin-like growth factor 1 (IGF-1) is a pluripotent growth factor with multiple functions in the peripheral and central nervous system. It supports neuronal survival and axon growth ${ }^{5,6}$. IGF-1 was found to protect the motoneurons ${ }^{7}$. In ALS patients plasma IGF-1 levels were reduced, suggesting that the Growth hormone (GH)/ IGF-1 axis could be a serological marker of some specific neuronal degeneration ${ }^{8}$. The results of experimental studies indicate that low IGF-1 concentrations could play a role in the course of ALS disease by accelerating neurodegenerative changes and worsening clinical symptoms ${ }^{9}$. Research in mice suggested that IGF1-related mitochondrial protection might also play a role ${ }^{10}$. Increasing muscle derived IGF-1 was found protective in mouse models of $\mathrm{ALS}^{11}$, and delivering IGF-1 in the CNS also led to increased survival ${ }^{12,13}$. Understanding the IGF-1 system in neurons, including the regulation of IGF-1 availability and signaling mechanisms, could be an important aspect for development of ALS therapeutic approaches ${ }^{14}$.

${ }^{1}$ Institute of Epidemiology and Medical Biometry, Ulm University, Ulm, Germany. ${ }^{2}$ Department of Neurology, Ulm University, Ulm, Germany. ${ }^{3}$ Deutsches Herzzentrum München, Technische Universität München, Munich, Germany. ${ }^{4}$ DZHK (German Centre for Cardiovascular Research), partner site Munich Heart Alliance, Munich, Germany. ${ }^{5}$ INSERM U1118, Université de Strasbourg, Strasbourg, France. *email: dietrich.rothenbacher@uni-ulm.de 
The objective of this study was to analyze the associations of serum IGF-1 concentrations with the risk of ALS in a population-based case-control study. Furthermore, we investigated the association of IGF-1 serum concentration with prognosis of ALS in a cohort-design in ALS-cases only.

\section{Material and Methods}

Study design and study population. The ALS registry Swabia has been described previously in detail ${ }^{15-17}$. In brief, it is a population-based clinical-epidemiological registry with the aim to collect data on all newly diagnosed ALS cases in Swabia, a defined geographic region with approximately 8.4 million inhabitants in the SouthWest of Germany.

All reported ALS cases were defined by the diagnosis of possible, probable or definite ALS according to the revised El Escorial criteria by an experienced neurologist. Notifications of patients with suspected ALS were tracked and evaluated during the clinical course by the registry.

Patients prospectively registered between October 01, 2010 and June 30, 2014 were asked to provide informed consent to participate in a population-based case-control study. For each case $(\mathrm{N}=289)$, two sex and age frequency-matched control subjects $(\mathrm{N}=504)$ were randomly selected from the general population as registered in the regional registry office ("Einwohnermeldeamt"). The thus identified subjects were contacted by postal mail and invited to participate in the study. After written informed consent was obtained, study nurses visited the participants for a standardized interview and convenience blood sampling. Median time since the last meal was 3.2 hours in ALS cases and 3.2 hours in controls. The standardized instruments and tests were performed identically in ALS-cases and controls. On population-level in the target population in Swabia, response in cases was $65 \%$ (20\% refused and 15\% could not been contacted) and in the population-based controls $19 \%$ (39\% refused and $42 \%$ did not respond after several attempts to get in contact per mail and telephone).

In addition, ALS cases were actively followed-up and interviewed on a yearly basis. To update vital status record linkage with the central registration office in Baden-Württemberg and the local registration offices in Bavaria were performed (last update October $16^{\text {th }}, 2018$ ). In case of death, the date of death was obtained from the local registration office.

Ethics statement. International, national and state rules were followed implementing the ALS registry Swabia. We obtained full ethical approval of the ethical committees of the Ulm University and the regional physician chambers ("Landesaerztekammer Baden-Wuerttemberg" and "Landesaerztekammer Bayern").

Laboratory measurements. According to a common standard protocol for cases and controls, blood samples were transported in cooled containers to the study center. Serum was obtained by centrifugation for $10 \mathrm{~min}$ at $2000 \mathrm{RPM} \times \mathrm{g}$ and $4^{\circ} \mathrm{C}$ (Heraeus Multifuge $3 \mathrm{~S}-\mathrm{R}$, Fa. Thermofischer). Blood specimens were transferred into $0.5-1.0 \mathrm{ml}$ aliquots with screw tops on the same day and stored at $-80^{\circ}$ Celsius until further analysis. IGF-1 (ng/ $\mathrm{mL}$ ) was measured in serum (human IGF-1 Quantikine, R\&D Systems). The lower detection limit of IGF-1 in this assay was approximately $0.026 \mathrm{ng} / \mathrm{mL}$. The inter-assay coefficient of variation (CV) was $12.5 \%$. Further details can be found in the product data sheet of the manufacturer. All laboratory analyses were performed in blinded fashion at the Biomarker Laboratory of the Department of Internal Medicine II-Cardiology, Ulm University Medical Center.

Statistical methods. Conditional logistic regression was used to calculate multivariable odds ratios (OR) and $95 \%$ confidence intervals (CI) for the association of ALS with quartiles of serum IGF-1 concentrations. Quartile cut-points were calculated based on the distribution in controls. Models were stratified for age groups and adjusted for duration of school education, occupational work intensity, smoking (ever, never), family history of ALS, BMI, and diabetes mellitus. The models are based on data with full set of covariates. Beside quartiles we also split the top quartile into two categories $\left(75-<90^{\text {th }}\right.$ and $\geq 90^{\text {th }}$ percentile) to further investigate associations with more extreme values.

In the cohort part Cox proportional hazards models adjusted for age, diagnostic delay, site of onset and ALS-functional rating scale-revised (FRS-R) were applied to calculate hazard ratios (HRs) for overall survival. Survival times were censored at the date of the last systematic mortality update (October $16^{\text {th }}, 2018$ ). In addition, we used cubic restricted splines (with knots at 10,50, and 90\% percentiles) on IGF-1 as continuous variable to model a possible nonlinear association with mortality. Sensitivity analyses excluding the El Escorial categories "clinically suspected" and "clinically possible" were performed in the adjusted model.

We calculated ALS-FRS-R decline, as (48 - ALS-FRS-R at interview) divided by (time from disease onset to interview in month), as marker of disease progression. The association of IGF-1 and ALS-FRS-R decline was modeled using cubic restricted splines (with knots at 10, 50, and 90\% percentiles) adjusted for age, sex and time since last meal.

All provided p-values are two-sided. The statistical software package SAS release 9.4 (SAS Institute, Cary, NC, USA) was used.

\section{Results}

The case-control study comprised 294 ALS cases (60.2\% men) with a mean age of 65.4 (SD 11.0) years and 504 controls (59.3\% men) with a mean age of 66.3 (SD 10.3) years (Table 1). Compared to controls, ALS patients were characterized by lower school education, BMI, occupational work intensity, respectively and median concentration of serum IGF-1 were slightly higher in ALS cases than in controls (101.0 vs. $99.7 \mathrm{ng} / \mathrm{ml})$. Most ALS cases showed lumbar (34.0\%), bulbar (31.0\%) or cervical (25.5\%) onset. According to the revised El Escorial criteria, more than $70 \%$ of the ALS cases had a probable or definite diagnosis.

The comparison between ALS cases and controls revealed differences in school education for the category 10 years or more ( $44.7 \%$ vs. $54.9 \%)$ and heavy occupational work intensity (23.0\% vs. $12.9 \%)$, and prevalence 


\begin{tabular}{|c|c|c|c|c|}
\hline & $\mathbf{N}_{\text {Cases }}$ & ALS-cases & $\mathbf{N}_{\text {Controls }}$ & Control subjects \\
\hline Age (years), mean (SD) & 294 & $65.4(11.0)$ & 504 & $66.3(9.8)$ \\
\hline Sex & 294 & & 504 & \\
\hline Male, N (\%) & & $177(60.2)$ & & $299(59.3)$ \\
\hline School education, $\mathrm{N}(\%)$ & 294 & & 501 & \\
\hline$<10^{\text {th }}$ grade & & $163(55.4)$ & & $226(45.1)$ \\
\hline$\geq 10^{\text {th }}$ grade & & $131(44.7)$ & & $275(54.9)$ \\
\hline Smoking & 291 & & 503 & \\
\hline Ever, $\mathrm{N}(\%)$ & & $134(46.1)$ & & $242(48.1)$ \\
\hline BMI $\left(\mathrm{kg} / \mathrm{m}^{2}\right)$, mean $(\mathrm{SD})$ & 294 & $24.6(4.1)$ & 502 & $26.5(4.0)$ \\
\hline$<23, \mathrm{~N}(\%)$ & & $110(37.4)$ & & $86(17.1)$ \\
\hline $23-<25, \mathrm{~N}(\%)$ & & $66(22.5)$ & & $113(22.5)$ \\
\hline $25-<28, \mathrm{~N}(\%)$ & & $63(21.4)$ & & $151(30.1)$ \\
\hline$\geq 28, \mathrm{~N}(\%)$ & & $55(18.7)$ & & $152(30.3)$ \\
\hline Family history of ALS, N (\%) & 290 & & 504 & \\
\hline Positive & & $12(4.1)$ & & $2(0.4)$ \\
\hline Occupational work intensity, $\mathrm{N}$ (\%) & 283 & & 498 & \\
\hline Light (mainly sitting) & & $102(36.0)$ & & $231(46.4)$ \\
\hline Moderate (standing and walking) & & $116(41.0)$ & & $203(40.8)$ \\
\hline Heavy (physically demanding) & & $65(23.0)$ & & $64(12.9)$ \\
\hline Diabetes mellitus prevalence, $\mathrm{N}(\%)$ & 285 & $26(9.1)$ & 492 & $54(11.0)$ \\
\hline IGF-1 (ng/ml), median (Q1,Q3) & 294 & $101.0(81.2,123.0)$ & 504 & $99.5(80.7,120.0)$ \\
\hline Time since last meal before blood sampling (h), median (Q1,Q3) & 284 & $3.2(0.5,18.5)$ & 487 & $3.2(0.25,17.5)$ \\
\hline Time of blood sampling (hh:mm), median (Q1, Q3) & 288 & 11:00 (10:00, 12:30) & 496 & $12: 30(11: 30,13: 45)$ \\
\hline \multicolumn{5}{|l|}{ Clinical characteristics of ALS-cases } \\
\hline \multicolumn{5}{|l|}{ Site of onset, $\mathrm{N}(\%)$} \\
\hline Bulbar & \multirow{5}{*}{294} & $91(31.0)$ & & \\
\hline Cervical & & 75 (25.5) & & \\
\hline Thoracic & & $13(4.4)$ & & \\
\hline Lumbar & & $100(34.0)$ & & \\
\hline Uncertain & & $15(5.1)$ & & \\
\hline \multicolumn{5}{|l|}{ Revised El Escorial criteria, N (\%) } \\
\hline Clinically suspected & \multirow{5}{*}{289} & $47(16.3)$ & & \\
\hline Clinically possible & & $36(12.5)$ & & \\
\hline Clinically probable & & $95(32.9)$ & & \\
\hline Clinically probable - lab. supported & & $81(28.0)$ & & \\
\hline Clinically definite & & $30(10.4)$ & & \\
\hline ALS-FRS, median (Q1, Q3) & 293 & $39.0(34.0,43.0)$ & & \\
\hline Diagnostic delay (month), median (Q1, Q3) & 294 & $5.0(2.7,9.0)$ & & \\
\hline Diagnosis to baseline visit (month), median (Q1, Q3) & 294 & $3.6(2.1,6.0)$ & & \\
\hline
\end{tabular}

Table 1. Main characteristics of ALS patients and control subjects.

of diabetes mellitus which was reported by $9.1 \%$ of ALS cases and $11.0 \%$ of controls. Compared to participants until the age of 65 years, older age was associated with lower IGF-1 concentrations (p-value $<0.001$, Supplemental Table 1).

In the fully adjusted model (Table 2), IGF-1 serum concentrations were not associated with the risk of ALS neither in crude nor in fully adjusted models (top vs. bottom quartile: OR 1.12; 95\% CI 0.71,1.77, p for trend 0.53). However, when the upper quartile was further divided, increased ALS risk for increased IGF- 1 concentrations become somewhat more prominent $\left(90^{\text {th }}\right.$ percentile vs. bottom quartile: OR 1.38 ; $95 \%$ CI $0.79-2.43$, p for trend 0.37), however, the $95 \% \mathrm{CI}$ of the point estimate included the null-effect value. By using restricted cubic splines and IGF-1 serum concentrations as a continuous measure we did not find evidence for an association with ALS risk (p-value 0.21, Supplemental Fig. 1). Sensitivity analyses with "clinically suspected" and "clinically possible" cases only suggested an increased point estimate for top vs. bottom quartile with an OR of 1.24 (p for trend 0.33), but the $95 \%$ CI from 0.73 to 2.09 was wide and also included the null-effect values (Supplemental Table 2).

In the cohort part, which included the ALS-cases only, 243 deaths in 293 cases were identified during a median follow-up of 67.6 months. Table 3 shows the characteristics of these patients. Median IGF-1 concentration was $52.0 \mathrm{ng} / \mathrm{ml}$ in deceased compared to $55.0 \mathrm{ng} / \mathrm{ml}$ in ALS patients who survived.

The evaluation of IGF-1 in quartiles revealed no clear pattern of the associated HR, i.e. the HR corresponding to the top vs. bottom quartile was 0.90 (95\% CI; 0.61-1.31, Table 4). The top quartile has been divided in the 


\begin{tabular}{|c|c|}
\hline & Odds ratio $(95 \%-\mathrm{CI})$ \\
\hline \multicolumn{2}{|l|}{ Crude $\left(\mathrm{N}_{\text {Cases }}=294, \mathrm{~N}_{\text {Controls }}=504\right)^{\mathrm{a}}$} \\
\hline Bottom quartile $(<80.8 \mathrm{ng} / \mathrm{ml})$ & (ref.) 1.00 \\
\hline $2^{\text {nd }}$ quartile $(80.8-<99.9 \mathrm{ng} / \mathrm{ml})$ & $0.91(0.60,1.38)$ \\
\hline $3^{\text {rd }}$ quartile $(99.9-<121 \mathrm{ng} / \mathrm{ml})$ & $1.06(0.70,1.60)$ \\
\hline Top quartile $(\geq 121 \mathrm{ng} / \mathrm{ml})$ & $0.96(0.63,1.45)$ \\
\hline $\mathrm{p}$-value for trend & 0.97 \\
\hline \multicolumn{2}{|l|}{ Adjusted $\left(\mathrm{N}_{\text {Cases }}=277, \mathrm{~N}_{\text {Controls }}=494\right)^{\mathrm{b}}$} \\
\hline Bottom quartile $(<80.8 \mathrm{ng} / \mathrm{ml})$ & (ref.) 1.00 \\
\hline $2^{\text {nd }}$ quartile $(80.8-<99.9 \mathrm{ng} / \mathrm{ml})$ & $0.93(0.60,1.42)$ \\
\hline $3^{\text {rd }}$ quartile $(99.9-<121 \mathrm{ng} / \mathrm{ml})$ & $1.09(0.71,1.69)$ \\
\hline Top quartile $(\geq 121 \mathrm{ng} / \mathrm{ml})$ & $1.09(0.71,1.67)$ \\
\hline p-value for trend & 0.56 \\
\hline \multicolumn{2}{|c|}{ Add. adj. for diabetes and BMI $\left(\mathrm{N}_{\text {Cases }}=260, \mathrm{~N}_{\text {Controls }}=464\right)^{\mathrm{c}}$} \\
\hline Bottom quartile $(<80.8 \mathrm{ng} / \mathrm{ml})$ & (ref.) 1.00 \\
\hline $2^{\text {nd }}$ quartile $(80.8-<99.9 \mathrm{ng} / \mathrm{ml})$ & $0.91(0.57,1.45)$ \\
\hline $3^{\text {rd }}$ quartile $(99.9-<121 \mathrm{ng} / \mathrm{ml})$ & $1.02(0.64,1.62)$ \\
\hline Top quartile $(\geq 121 \mathrm{mg} / \mathrm{l})$ & $1.12(0.71,1.77)$ \\
\hline p-value for trend & 0.53 \\
\hline $75-<90^{\text {th }}$ percentile $(121->140 \mathrm{ng} / \mathrm{ml})$ & $0.94(0.54-1.62)$ \\
\hline $90^{\text {th }}($ percentile $\geq 140 \mathrm{ng} / \mathrm{ml})$ & $1.38(0.79,2.43)$ \\
\hline
\end{tabular}

Table 2. Odds ratios for ALS by quartiles of serum IGF-1 concentrations. ${ }^{\mathrm{a} C o n t r o l l e d ~ f o r ~ a g e ~ a n d ~ s e x . ~}$

${ }^{\mathrm{b}}$ Additionally adjusted for school education, occupational work intensity, smoking (ever) and family history of ALS. ${ }^{\mathrm{c}}$ As ${ }^{\mathrm{b}}$ but additionally adjusted for diabetes, body mass index (BMI), and time since last meal.

\begin{tabular}{|l|l|l|l|l|}
\hline & $\mathbf{N}_{\text {Deceased }}$ & Deceased & $\mathbf{N}_{\text {Survived }}$ & Survived \\
\hline Age (years), mean (SD) & 243 & $66.5(10.5)$ & 50 & $60.5(11.7)$ \\
\hline Sex & 243 & & 50 & \\
\hline Male, N (\%) & & $138(56.8)$ & & $38(76.0)$ \\
\hline BMI (kg/m), mean (SD) & 243 & $24.5(4.0)$ & 50 & $24.8(4.5)$ \\
\hline Diagnostic delay (month), median (Q1, Q3) & 243 & $5.0(2.7,8.5)$ & 50 & $6.0(2.5,11.1)$ \\
\hline ALS-FRS, median (Q1, Q3) & 242 & $38.5(34,42)$ & 50 & $41(38,45)$ \\
\hline IGF-1 (ng/ml), median (Q1, Q3) & 243 & $101.0(82.2,118.0)$ & 50 & $105.5(74.6,137.0)$ \\
\hline
\end{tabular}

Table 3. Characteristics of ALS patients $(\mathrm{N}=293)$ with mortality follow-up by survival status.

$75-<90^{\text {th }}$ and $\geq 90^{\text {th }}$ percentiles in order to analyze more refined association in the top quartile. The splitting revealed an HR of 0.87 (95\%CI 0.54-1.40) and HR of 0.93 (95\% CI 0.58-1.48), respectively. However, the evaluation of the prognostic value of IGF-1 serum concentrations as a continuous measure by using restricted cubic splines revealed a nonlinear association with reduced mortality for high IGF-1 levels (p-value 0.01, Fig. 1). In addition, IGF-1 serum concentrations were in a similar nonlinear manner associated with ALS-FRS-R decline assessed at baseline (Supplemental Fig. 2, $\mathrm{p}=0.02$ ).

\section{Discussion}

In this population-based case-control study in Southern Germany, serum IGF-1 concentrations were not associated with risk of ALS. In the cohort of ALS patients, however, we found evidence for an inverse association between high serum IGF-1 concentrations and overall survival.

Our results in the ALS cohort concerning prognosis are in line with observations of others. In ALS patient with longer survival, peripheral IGF- 1 concentrations were increased by $58 \%$ compared to controls ${ }^{18}$, suggesting that higher IGF-1 concentrations may be associated with favorable survival. Beauverd et al. (2012) performed a meta-analysis including 779 patients from three studies, which, however, the authors saw as seriously compromised by details of trial designs ${ }^{19}$. The pooled results, however, of two trials suggested that treatment with recombinant human IGF-1 might be beneficial, but in one study no benefit in survival was found ${ }^{19}$. In addition, our observation that higher IGF-1 concentration is associated with longer survival is consistent with experimental research, showing that IGF-1 acts as a mitochondrial protector in the ALS cell and mouse model ${ }^{10}$. A results of a recent trial on IGF-1 in the treatment of spinal and bulbar muscular atrophy (SBMA), a rare motoneuron disease of the peripheral muscle with slow progression, did not improve muscle strength or function ${ }^{20}$.

Indeed, higher circulating concentrations of IGF-1 were related to increased survival in ALS mouse model ${ }^{21}$. IGF-1 and its binding proteins were also affected in muscles of ALS patients ${ }^{22}$. Importantly, IGF-1 led to increased survival of ALS patients in most ${ }^{11-13,23}$ but not all ${ }^{24}$ studies. 


\begin{tabular}{|c|c|}
\hline & Hazard ratio $(95 \%-\mathrm{CI})$ \\
\hline \multicolumn{2}{|l|}{ Crude $\left(\mathrm{N}_{\text {Deceased }}=243, \mathrm{~N}_{\text {Survived }}=50\right)^{\mathrm{a}}$} \\
\hline Bottom quartile $(<80.8 \mathrm{ng} / \mathrm{ml})$ & (ref.) 1.00 \\
\hline $2^{\text {nd }}$ quartile $(80.8-<99.9 \mathrm{ng} / \mathrm{ml} \mathrm{l})$ & $1.29(0.90,1.85)$ \\
\hline $3^{\text {rd }}$ quartile $(99.9-<121 \mathrm{ng} / \mathrm{ml})$ & $1.17(0.82,1.66)$ \\
\hline Top quartile $(\geq 121 \mathrm{ng} / \mathrm{ml})$ & $0.97(0.67,1.40)$ \\
\hline $\mathrm{p}$-value for trend & 0.78 \\
\hline \multicolumn{2}{|l|}{ Adjusted $\left(\mathrm{N}_{\text {Deceased }}=242, \mathrm{~N}_{\text {Survived }}=50\right)^{\mathrm{b}}$} \\
\hline Bottom quartile $(<80.8 \mathrm{ng} / \mathrm{ml})$ & (ref.) 1.00 \\
\hline $2^{\text {nd }}$ quartile $(80.8-<99.9 \mathrm{ng} / \mathrm{ml})$ & $1.13(0.78,1.64)$ \\
\hline $3^{\text {rd }}$ quartile $(99.9-<121 \mathrm{ng} / \mathrm{ml})$ & $1.22(0.84,1.76)$ \\
\hline Top quartile $(\geq 121 \mathrm{ng} / \mathrm{ml})$ & $0.90(0.61,1.31)$ \\
\hline $\mathrm{p}$-value for trend & 0.66 \\
\hline $75-<90^{\text {th }}$ percentile $(121->140 \mathrm{ng} / \mathrm{ml})$ & $0.87(0.54,1.40)$ \\
\hline $90^{\text {th }}$ percentile $(\geq 140 \mathrm{ng} / \mathrm{ml})$ & $0.93(0.58,1.48)$ \\
\hline
\end{tabular}

Table 4. Hazard ratio by quartiles of serum IGF-1 concentrations among ALS patients. ${ }^{a}$ Controlled for age and sex. ${ }^{b}$ Additionally adjusted for diagnostic delay, site of onset, ALS-FRS and body mass index.

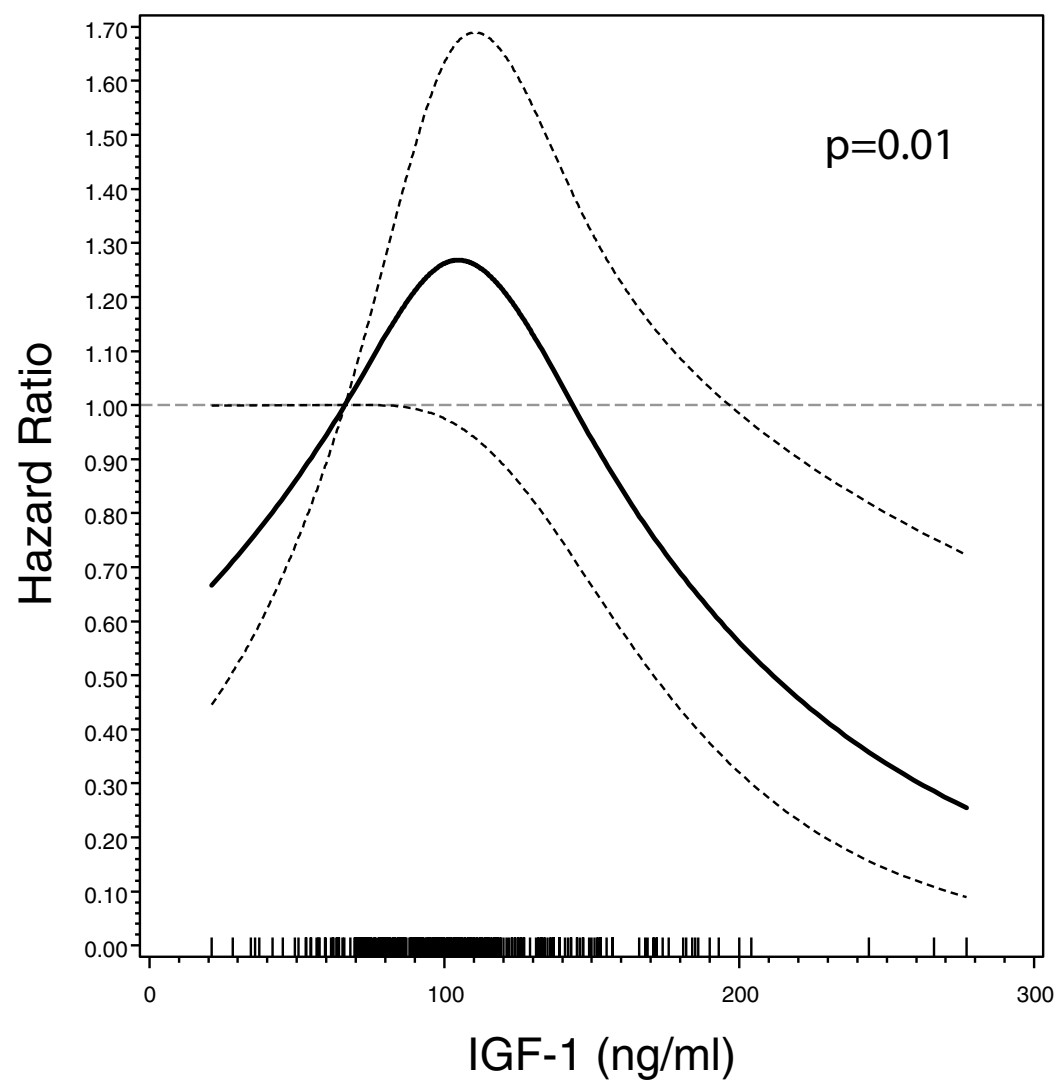

Figure 1. Serum IGF-1 concentration and HR (95\% confidence band) of ALS mortality among 293 ALS patients by cubic splines, adjusted for age, sex, diagnostic delay, site of onset, ALS-FRS, and body mass index. The dashed grey line represents the reference value $(\mathrm{HR}=1$ at $66.3 \mathrm{ng} / \mathrm{ml})$. Bottom rugs represent measured IGF-1 values.

Multiple mechanisms elicited by IGF-1 might account for the observed increased survival in patients with higher circulating IGF-1. IGF-1 displays high neurotrophic properties, which could protect motor neurons and increase survival in ALS ${ }^{25}$. IGF-1 has also anabolic actions on skeletal muscle, especially upon denervation $^{26}$, which might be beneficial in ALS. Indirectly, increased circulating IGF-1 could be a fingerprint of higher GH-IGF1 axis activity, and GH is able to modulate oligodendroglial cell survival and myelination in the CNS ${ }^{27}$. Interestingly growth hormone secretion was dysregulated in both patients and mouse models of ALS ${ }^{28}$. Results from experimental studies indicate a circadian control of IGF-I production ${ }^{29,30}$. In our study the time of blood 
sampling was in median about 1.5 hours earlier in ALS cases than in control subjects, with large overlap in the distribution. Furthermore, it can be speculated whether atrophy of the hypothalamus in ALS patients is related to the different IFG-I levels ${ }^{31}$.

Since IGF-1 is also related to energy metabolism and body weight ${ }^{32}$, our current findings are consistent with former observations concerning BMI and adipokines as well as the findings on retinol binding protein (RBP) 4 and the prognosis of ALS ${ }^{3,19,33}$. Importantly, however, the observed protective effect of higher IGF-1 was observed upon adjustment of BMI, suggesting that it is not fully mediated by BMI as marker for fat mass. Thus, the longer survival of patients with higher IGF-1 levels could be related to direct biological actions of IGF-1, to an overactivation of a protective GH-IGF-1 pathway or to altered IGF-1 levels in patients with a favorable metabolic status.

Strengths of our study are its relatively large sample size and the virtually complete follow-up of the ALS patient cohort ${ }^{17}$. In addition, in the case-control part we carefully matched for sex, age as well as geographic region and used multivariable analysis to further adjust for potential confounders such as physical activity, levels of education and smoking status. Yet, adjustment for diabetes and BMI did not substantially change the risk estimates. In addition, IGF-1 was measured according to a standard protocol under blinded conditions.

However, there are also limitations which need to be considered. Residual confounding cannot be ruled out. In addition, in order to account for the blood sampling at convenience we adjusted for the time since last meal in the analyses. When generalizing the results of the case-control study the low participation rate among the controls should be considered. However, IGF-1 as prognostic factor was analyzed in a cohort of ALS patients with median follow-up of 67.6 months which is representative for the entire ALS registry Swabia ${ }^{17}$. Furthermore, when looking on the results we have to keep the limited sample size in both study parts in mind. The power of the case-control study was insufficient to detect a weak association between IGF-1-serum concentrations and risk of ALS. It was about $80 \%$ to detect an OR of 1.8 (i.e. a minimum risk increase of $80 \%$ ) at $\alpha=0.05$ associated with the upper quartile compared to the bottom one. In the cohort part, the power to detect was HR 0.6 (i.e. a risk reduction of $40 \%$ ) under the same conditions.

In summary, our study showed no clear association of serum IGF-1 concentration with ALS risk but with the prognosis of ALS, suggesting that higher IGF-1 concentration could increase survival. Further research including a prospective design and other biological markers is necessary to clarify the role of IGF-1 in disease progression of ALS.

\section{Data availability}

Due to ethical restrictions regarding data protection issues and the study specific consent text and procedure, the data cannot be made publicly available, but data are available to all interested researchers upon request.

Received: 12 July 2019; Accepted: 20 December 2019;

Published online: 20 January 2020

\section{References}

1. Ludolph, A. C., Brettschneider, J. \& Weishaupt, J. H. Amyotrophic lateral sclerosis. Curr. Opin. Neurol. 25, 530-535 (2012).

2. Dupuis, L., Pradat, P.-F., Ludolph, A. C. \& Loeffler, J.-P. Energy metabolism in amyotrophic lateral sclerosis. Lancet Neurol. 10, 75-82 (2011).

3. Peter, R. S. et al. Life course body mass index and risk and prognosis of amyotrophic lateral sclerosis: results from the ALS registry Swabia. Eur. J. Epidemiol. 32, 901-908 (2017).

4. Nagel, G. et al. Adipokines, C-reactive protein and Amyotrophic Lateral Sclerosis - results from a population- based ALS registry in Germany. Sci. Rep. 7, 4374 (2017).

5. Park, S. E., Park, C.-Y. \& Sweeney, G. Biomarkers of insulin sensitivity and insulin resistance: Past, present and future. Crit. Rev. Clin. Lab. Sci. 52, 180-190 (2015).

6. Rauskolb, S., Dombert, B. \& Sendtner, M. Insulin-like growth factor 1 in diabetic neuropathy and amyotrophic lateral sclerosis. Neurobiol. Dis. 97, 103-113 (2017).

7. Lewis, M. E. et al. Insulin-like growth factor-I: potential for treatment of motor neuronal disorders. Exp. Neurol. 124, 73-88 (1993).

8. Torres-Aleman, I., Barrios, V. \& Berciano, J. The peripheral insulin-like growth factor system in amyotrophic lateral sclerosis and in multiple sclerosis. Neurology 50, 772-776 (1998).

9. Maiese, K. Novel applications of trophic factors, Wnt and WISP for neuronal repair and regeneration in metabolic disease. Neural Regen. Res. 10,518-528 (2015).

10. Wen, D. et al. The role of insulin-like growth factor 1 in ALS cell and mouse models: A mitochondrial protector. Brain Res. Bull. 144, 1-13 (2018).

11. Dobrowolny, G. et al. Muscle expression of a local Igf-1 isoform protects motor neurons in an ALS mouse model. J. Cell Biol. 168, 193-199 (2005).

12. Dodge, J. C. et al. AAV4-mediated expression of IGF-1 and VEGF within cellular components of the ventricular system improves survival outcome in familial ALS mice. Mol. Ther. 18, 2075-2084 (2010).

13. Lepore, A. C. et al. Intraparenchymal spinal cord delivery of adeno-associated virus IGF-1 is protective in the SOD1G93A model of ALS. Brain Res. 1185, 256-265 (2007).

14. Sakowski, S. A., Schuyler, A. D. \& Feldman, E. L. Insulin-like growth factor-I for the treatment of amyotrophic lateral sclerosis. Amyotroph. Lateral Scler. 10, 63-73 (2009).

15. Nagel, G., Ünal, H., Rosenbohm, A., Ludolph, A. C. \& Rothenbacher, D. Implementation of a population-based epidemiological rare disease registry: study protocol of the amyotrophic lateral sclerosis (ALS) - registry Swabia. BMC Neurol. 13, 22 (2013).

16. Uenal, H. et al. Incidence and Geographical Variation of Amyotrophic Lateral Sclerosis (ALS) in Southern Germany - Completeness of the ALS Registry Swabia. PLoS One 9, e93932 (2014).

17. Rosenbohm, A. et al. Epidemiology of amyotrophic lateral sclerosis in Southern Germany. J. Neurol. 264, 749-757 (2017).

18. Hosback, S. et al. Circulating insulin-like growth factors and related binding proteins are selectively altered in amyotrophic lateral sclerosis and multiple sclerosis. Growth Horm. IGF Res. 17, 472-479 (2007).

19. Beauverd, M., Mitchell, J. D., Wokke, J. H. J. \& Borasio, G. D. Recombinant human insulin-like growth factor I (rhIGF-I) for the treatment of amyotrophic lateral sclerosis/motor neuron disease. Cochrane Database Syst. Rev. 11, CD002064 (2012).

20. Grunseich, C. et al. Safety, tolerability, and preliminary efficacy of an IGF-1 mimetic in patients with spinal and bulbar muscular atrophy: a randomised, placebo-controlled trial. Lancet Neurol. 17, 1043-1052 (2018). 
21. Fergani, A. et al. A mutation in the dynein heavy chain gene compensates for energy deficit of mutant SOD1 mice and increases potentially neuroprotective IGF-1. Mol. Neurodegener. 6, 26 (2011).

22. Lunetta, C. et al. Impaired expression of insulin-like growth factor-1 system in skeletal muscle of amyotrophic lateral sclerosis patients. Muscle Nerve 45, 200-208 (2012).

23. Lin, H. et al. Intramuscular Delivery of scAAV9-hIGF1 Prolongs Survival in the hSOD1G93A ALS Mouse Model via Upregulation of D-Amino Acid Oxidase. Mol. Neurobiol. 55, 682-695 (2018).

24. Messi, M. L., Clark, H. M., Prevette, D. M., Oppenheim, R. W. \& Delbono, O. The lack of effect of specific overexpression of IGF-1 in the central nervous system or skeletal muscle on pathophysiology in the G93A SOD-1 mouse model of ALS. Exp. Neurol. 207, $52-63(2007)$

25. Doré, S., Kar, S. \& Quirion, R. Rediscovering an old friend, IGF-I: potential use in the treatment of neurodegenerative diseases. Trends Neurosci. 20, 326-331 (1997)

26. Musarò, A., McCullagh, K. J., Naya, F. J., Olson, E. N. \& Rosenthal, N. IGF-1 induces skeletal myocyte hypertrophy through calcineurin in association with GATA-2 and NF-ATc1. Nature 400, 581-585 (1999).

27. Hua, K., Forbes, M. E., Lichtenwalner, R. J., Sonntag, W. E. \& Riddle, D. R. Adult-onset deficiency in growth hormone and insulinlike growth factor-I alters oligodendrocyte turnover in the corpus callosum. Glia 57, 1062-1071 (2009).

28. Steyn, F. J. et al. Impairments to the GH-IGF-I axis in hSOD1G93A mice give insight into possible mechanisms of GH dysregulation in patients with amyotrophic lateral sclerosis. Endocrinology 153, 3735-3746 (2012).

29. Chaudhari, A., Gupta, R., Patel, S., Velingkaar, N. \& Kondratov, R. Cryptochromes regulate IGF-1 production and signaling through control of JAK2-dependent STAT5B phosphorylation. Mol. Biol. Cell 28, 834-842 (2017).

30. Breit, A. et al. Insulin-like growth factor- 1 acts as a zeitgeber on hypothalamic circadian clock gene expression via glycogen synthase kinase-33 signaling. J. Biol. Chem. 293, 17278-17290 (2018).

31. Gorges, M. et al. Hypothalamic atrophy is related to body mass index and age at onset in amyotrophic lateral sclerosis. J. Neurol. Neurosurg. Psychiatry 88, 1033-1041 (2017).

32. Hawkes, C. P. \& Grimberg, A. Insulin-Like Growth Factor-I is a Marker for the Nutritional State. Pediatr. Endocrinol. Rev. 13, 499-511 (2015)

33. Rosenbohm, A. et al. Association of Serum Retinol-Binding Protein 4 Concentration With Risk for and Prognosis of Amyotrophic Lateral Sclerosis. JAMA Neurol. 75, 600-607 (2018).

\section{Acknowledgements}

We thank the Ilonka Kraft-Oberbeck, Ines Dobias and Nicola Lämmle for their excellent field work, Gerlinde Trischler for expert technical assistance and Gertrud Feike, Sarah Enderle, and Birgit Och for excellent data management and technical support. We thank the members of the ALS Registry Swabia Study group: Alber B., Klinikum Günzburg, Department of Neurology. Andres F., Kreiskliniken Reutlingen, Department of Neurology. Arnold G., Klinikum Sindelfingen-Böblingen, Department of Neurology. Asshauer I., Klinikum Friedrichshafen, Department of Psychiatry and Psychotherapy. Baezner H., Bürgerhospital Stuttgart, Department of Neurology. Baier H., ZFP Südwürttemberg Weissenau, Department of Epileptology. Beattie J., Ostalb-Klinikum Aalen, Department of Neurology. Becker T., University of Ulm, Department of Psychiatry and Psychotherapy II. Behne F., ZFP Südwürttemberg Weissenau, Department of Epileptology. Bengel D., Oberschwabenklinik Ravensburg, Department of Neurology. Boertlein A., Bürgerhospital Stuttgart, Department of Neurology. Bracknies, V., Klinik Dietenbronn, Department of Neurology, Broer R., Klinikum am Weissenhof, Weinsberg, Department of Psychiatry and Psychotherapy. Connemann B., University of Ulm, Department of Psychiatry and Psychotherapy III. Dempewolf S., Klinikum Ludwigsburg, Department of Neurology. Dettmers C., Schmieder Kliniken Konstanz, Department of Neurology. Dieterich M., LMU München, Department of Neurology. Etzersdorfer E., Furtbachkrankenhaus Stuttgart, Department of Psychiatry and Psychotherapy. Freund, W., Biberach. Gersner T., ZfP Zwiefalten, Department of Psychiatry and Psychotherapy. Gold H.-J., Klinikum am Gesundbrunnen Heilbronn, Department of Neurology. Hacke, W., University of Heidelberg, Department of Neurology. Hamann G., Klinikum Günzburg, Department of Neurology. Hecht M., Bezirkskrankenhaus Kaufbeuren, Department of Neurology. Heimbach B., University of Freiburg, Department of Neurology. Hemmer B., TU München, Department of Neurology. Hendrich C., Klinikum Friedrichshafen, Department of Neurology. Herting B., Diakonie-Klinikum Schwäbisch Hall, Department of Neurology. Huber R., Klinikum Friedrichshafen, Department of Neurology. Huber-Hartmann K., Kliniken Landkreis Heidenheim, Department of Neurology. Hülser P.-J., Fachklinik Wangen, Department of Neurology. Jüttler E., Ostalb-Klinikum Aalen, Department of Neurology. Kammerer-Ciernioch J., Klinikum am Weissenhof, Weinsberg, Department of Psychiatry and Psychotherapy. Kaspar A., Oberschwabenklinik Ravensburg, Department of Neurology. Kern R., Klinikum Kempten, Department of Neurology. Kimmig H., Kliniken Schwenningen, Department of Neurology. Klebe, S., University of Würzburg, Department of Neurology. Kloetzsch C., Schmieder Kliniken Allensbach, Department of Neurology. Klopstock, T., LMU München, Department of Neurology. Kohler, A., Klinikum am Gesundbrunnen Heilbronn, Department of Neurology. Kuethmann A., Bezirkskrankenhaus Memmingen, Department of Psychiatry and Psychotherapy. Lewis D., Marienhospital Stuttgart, Department of Neurology. Lichy C., Klinikum Memmingen, Department of Neurology. Lindner A., Marienhospital Stuttgart, Department of Neurology. Lulé, D., University of Ulm, Department of Neurology. Mäurer M., Caritas Krankenhaus Bad Mergentheim, Department of Neurology. Maier-Janson W., Ravensburg. Metrikat J., Bundeswehrkrankenhaus Ulm, Department of Neurology. Meudt O., Klinikum Memmingen, Department of Neurology. Meyer A., Weissenau, Department of Neurology. Müller vom Hagen J., University of Tuebingen, Department of Neurology. Naegele A., Christophsbad Göppingen, Department of Neurology. Naumann M., Klinikum Augsburg, Department of Neurology. Neher K.-D., Vinzenz von Paul Hospital, Rottweil, Department of Neurology. Neuhaus O., Kliniken Landkreis Sigmaringen, Department of Neurology. Neusch C., Singen. Niehaus L., Klinikum Winnenden, Department of Neurology, Opherk C., Klinikum am Gesundbrunnen Heilbronn, Department of Neurology. Raape J., ZFP Südwürttemberg Weissenau, Department od Neurology. Ratzka P., Klinikum Augsburg, Department of Neurology. Rettenmayr C., Klinikum Esslingen, Department of Neurology. Riepe M.W., Klinikum Günzburg, Department of Gerontopsychiatry. Rothmeier J., ZFP Südwürttemberg Weissenau, Department of Neurology. Sabolek M., Klinik Biberach, Department of Neurology. Schabet M., Klinikum Ludwigsburg, 
Department of Neurology. Schell C., Kreiskliniken Reutlingen, Department of Neurology. Schlipf T., Klinikum Winnenden, Department of Psychiatry and Psychotherapy. Schmauss M., Bezirkskrankenhaus Augsburg, Department of Psychiatry and Psychotherapy. Schoels L., University of Tübingen, Department of Neurology. Schuetz K., Kliniken Schwenningen, Department of Neurology. Schweigert B., Caritas Krankenhaus Bad Mergentheim, Department of Neurology. Sommer N., Christophsbad Göppingen, Department of Neurology. Sperber W., Kliniken Esslingen, Department of Neurology. Steber C., Bezirkskrankenhaus Augsburg, Department of Psychiatry and Psychotherapy. Steber R., Bezirkskrankenhaus Memmingen, Department of Psychiatry and Psychotherapy. Stroick M., Klinikum Memmingen, Department of Neurology. Synofzik, M., University of Tübingen, Deartment of Neurology. Trottenberg T., Klinikum Winnenden, Department of Neurology. Tumani H., Klinikum Dietenbronn, Department of Neurology, Wahl C., Klinikum Kempten, Department of Neurology. Weber F., Bundeswehrkrankenhaus Ulm, Department of Neurology. Weiler M., University of Heidelberg, Department of Neurology. Weiller C., University of Freiburg, Department of Neurology. Wessig C., University of Würzburg, Department of Neurology. Winkler A., TU München, Department of Neurology. The ALS registry Swabia and this study have been supported by the German Research Council (DFG). The funders had no role in study design, data collection, data analysis, data interpretation, or writing of the report. All authors had full access to all data in the study and had final responsibility for the decision to submit the publication.

\section{Author contributions}

A.C.L., D.R. and G.N. conventionalized the study, A.C.L.; A.R. G.N. and R.S.P., were involved in the data collection, W.K. was responsible for biomarker measurements, D.R., G.N. and R.S.P. analyzed the data, all authors were involved in the interpretation of the data, G.N. drafted and revised the manuscript, G.N., R.S.P., A.R., W.K., L.D., D.R. and A.C.L. were involved in the draft and revision of the manuscript. All authors had full access to the data and take the responsibility for the integrity of the data and the accuracy of the data analysis.

\section{Competing interests}

The authors declare no competing interests.

\section{Additional information}

Supplementary information is available for this paper at https://doi.org/10.1038/s41598-020-57744-x.

Correspondence and requests for materials should be addressed to D.R.

Reprints and permissions information is available at www.nature.com/reprints.

Publisher's note Springer Nature remains neutral with regard to jurisdictional claims in published maps and institutional affiliations.

(c) (i) Open Access This article is licensed under a Creative Commons Attribution 4.0 International License, which permits use, sharing, adaptation, distribution and reproduction in any medium or format, as long as you give appropriate credit to the original author(s) and the source, provide a link to the Creative Commons license, and indicate if changes were made. The images or other third party material in this article are included in the article's Creative Commons license, unless indicated otherwise in a credit line to the material. If material is not included in the article's Creative Commons license and your intended use is not permitted by statutory regulation or exceeds the permitted use, you will need to obtain permission directly from the copyright holder. To view a copy of this license, visit http://creativecommons.org/licenses/by/4.0/.

(C) The Author(s) 2020 